\title{
éditorial
}

\section{Éclectisme et nutrition}

Nous le savions déjà, la nutrition est une discipline particulièrement éclectique. Selon les points de vue, cela constitue une faiblesse par rapport à des sciences au périmètre mieux ciblé, ou à l'inverse une force par les interrelations envisageables entre ses diverses composantes. Quoi qu'il en soit, cette diversité est source de curiosité et permet à l'intérêt de l'amateur comme du professionnel de rebondir d'une notion à l'autre.

Ce premier numéro de l'année 2006 reflète cet éclectisme. Éclectisme géographique, puisque ces articles vous feront passer de la France au Bénin, en passant par l'Atlantique Nord. Éclectisme des thèmes : le fer et les oméga-3, l'anthropologie et l'allergie alimentaire.

Bonne lecture.

Jacques FRICKER 